\title{
A Study on the Supply of Social-rented Housing in Kunming
}

\author{
Feng Yongli \\ Yunnan University of Finance and Economics, Kunming, P. R. China 650000 \\ (E-mail:574265304@qq.com)
}

\begin{abstract}
The supply of social-rented housing is one of the most important parts of housing security, which determines the depth of housing security and results in certain impact on social development. In order to get rid ofvarious constraints caused by the insufficient housing supply, this study analyzed the situation of social-rented housing in Kunming, and the paper pointed out that the provision of social-rented housing is much lower than it needed. And it suggested proving social-rented housing must be according to real demands of low-income family and poor areas. The local government should not take the policy of developing social-rented housing as an effective instrument to enhance local economy, and local government should supervise the distribution of social-rented housing with open and transparent information and process for a long run.
\end{abstract}

Keywords: Kunming, Social-rented housing, Supply, Demand.

\section{Introduction}

With the rapid development of the economy in socialist market in China, the national urbanization process has been accelerated with the improvement of people's living standard. Meanwhile, great progress has been achieved in terms of the national socialrented housing. As the urban population grows sharply in the process of urbanization, a large demand for housing has been produced. However, due to the constant rising price of land and commercial housing, people with lowincome cannot afford the housing, which leads to the increasingly severe urban housing issue. In order to improve the residential condition of low-income groups effectively, a series of policies have been introduced by Chinese government for the purpose of resolving the poor housing condition for low-income class and maintaining the social stability. These policies have played an important role, but a large part of residential problems still remain unsolved. Without proper settlement, these problems may prevent the pace of harmonious society construction of socialism in China.

\section{Analysis on Social-Rented Housing in} Kunming

With the continuous development of social economy in Kunming, Kunming government aims to resolve the residential difficulty problem of low-income families and reach the target of "having a place to live in" proposed in the report of 17th CPC National Congress, so it plans to invest approximately $¥ 1.04$ billion to support the construction of social-rented housing. Based on the construction of 12,000 socialrented housing[1], it aims to further increase the input in social-rented housing construction, especially the joint construction of social-rented housing together with state-owned enterprises. Next, the housing security mechanism focusing on the construction of social-rented housing is to be established in Kunming. Currently, it is striving to become the trial city of social-rented housing construction supported by housing fund in Yunnan Province.

By far, there have been 78,923 units of social-rented housing in Kunming, among which, 56,146 units are within the main urban range[2]. According to timeframe of construction, these social-rented housing will be completed by the end of this year. Before the 
Spring Festival of 2013, the first batch of random allocation includes four projects in Zehuiyuan, Zijuncun, Tianjiaobeilu and Renhexinjv, totally 4,790 units of public rental housing. After the Spring Festival of 2013, Jihuiyuan, Puhuiyuan, "Junfuhuacheng" Project, Guhuiyuan and Shenghuiyuan have been allocated subsequently for the construction of 20,000 units of social-rented housing[3].

\section{Analysis on the Demand of Social-Rented}

\section{Housing in Kunming}

At first, the main factor that influences the purchase of housing by residents is the market price of real estate, which directly affects their purchasecapacityand motivation. As a city with leading economic development in Yunnan, the economy of Kunming has been rapidly developed with the effective improvement of urbanization level.. Meanwhile, with the increasingly lack of land resources, the house pricing has been in a rise constantly. Therefore, the purchase ability of common commercial housing by residents has been reduced gradually and many people have strong demands for the social-rented housing. As we can see, the market price of real estate has led to certain change of the demands for social-rented housing.

The secondly, the level of national economic development can reflect the overall economic situation of a region, which not only reflects the development situation of all industries in China, but also influences the development of each industry. If the economic development level of a city is relatively high, its real estate industry will receive certain development as well as the increasing demands for housing by residents. Therefore, we can say that the economic development level of Kunming can affect its demand for social-rented housing.

The thirdly, the purchase power of urban residentscan be reflected from the per capita disposable income, which constitutes the purchase action with the integration of purchase desire. With the rapid economic development of Kunming and significant improvement of people's living standard, the demands for housing by Kunming residents have been higher and higher. Under such circumstance, purchase power is the only factor that may affect the real estate transaction, while the purchase power is determined by the per capita income of residents. Therefore, it implies that the per capita income of urban residents can affect the housing demands of residents by influencing their purchase power.

\section{Suggestions on Balancing Social-Rented Housing}

\subsection{Determining supply according to real demands}

Supply is determined by demand.Therefore, the quantity of short-term social-rented housing shall be conducted according to the real numbers of local lowincome families and demanding areas for socialrented housing rather than simply formulation of theoretical demands. Currently, due to the serious insufficiency of social-rented housing, municipalgovernments are unable to provide the social-rented housing according to the task issued by the province. So they should carry out and accelerate the provision of social-rented housing on the basis of the local real situation in order to meet the requirements for more and more low-income groups.

\subsection{Strengthening management capability}

Providing social-rented housing regularly should make a sound mechanism for accessing or exiting 
market. First of all, providing social-rented housing is not an effective approach to enhance the economic growth at the national level. Although the Ministry of Land and Resources has formulated a grand scheme for the provision of social-rented housing to each province and city, which might be helpful to increase the national economic growth and provide housing for low and medium income families, on the other hand, it could lead to the significant waste of land, construction fund and other resources, poor quality of housings.

Second, distributing social-rented housing should be open and fair. Therefore, local government should supervise the distribution of social-rented housing resource, and publish all information of social-rented housing to the public. The government should not take social-rented housing as a tool for making a profit and make a policy to prohibit all social-rented housing into the market.

Third, Local government should monitor the socialrented housing management by the media or the society. Anyone who is not qualified to enjoy socialrented housing is found, will be punished heavily.

\section{Conclusions}

The supply of social-rented housing is one of the most important parts of housing security, which determines the depth of housing security and results in certain impact on social development. In order to get rid ofvarious constraints caused by the insufficient housing supply, this study analyzed the situation of social-rented housing in Kunming, and the paper pointed out that the provision of socialrented housing is much lower than it needed. And it suggested proving social-rented housing must be according to real demands of low-income family and poor areas. The local government should not take the policy of developing social-rented housing as an effective instrument to enhance local economy, and local government should supervise the distribution of social-rented housing with open and transparent information and process for a long run.

\section{References}

(1) Chen Youyi. (2009). Study on the Influence of Social-rented housing Policy on Real Estate Market. Economic Review, 4, 32 -34

(2) Chen, Youyi. (2010). Problems and Countermeasures for the Implementation of Social-rented housingin China. Economic Review, 11

(3) Gu, Junqing. (2009). Defects and Perfection for Reform of Urban Housing Security Policy System in China. Modern Finance, 2, 47-52

(4) Luo, Jiayi. (2012). Thinking and Exploration for the Use and Management Mode of Social-rented housing. Chinese Real Estate, 3

(5) Luo, Yingguang. (2011). Having a Place to Live in: Theory and Practice of China's Construction of Social-rented housing. Beijing: Central Party SchoolPress

(6) Linlin, Wu Chunlan, Deng, Changchun. (2012). Thinking on the Access and Exit Mechanism of Social-rented housing. Chinese Audit Network

(7) Yangjun. (2010). China'sSocial-rented Housing System and Real Estate Development. Zhejiang Social Science 